\title{
Avrupa Deniz Levreği (Dicentrarchus labrax L.,1758) balıklarında aşılamanın beslenme ve gelişim üzerine etkisi
}

\section{The effect of vaccination on feeding and growth of European Sea Bass (Dicentrarchus labrax L.,1758)}

\section{Başak Özkesici1 • Ali Yıldırım Korkut*2 • Aysun Kop² • Ali Özcan Babaoğlu ${ }^{1}$}

${ }^{1}$ Ege Üniversitesi, Fen Bilimleri Enstitüsü, Yetiştiricilik Anabilim Dalı, 35100. Bornova İzmir

${ }^{2}$ Ege Üniversitesi, Su Ürünleri Fakültesi, Yetiştiricilik Bölümü, 35100. Bornova Izmir

*Corresponding author: ali.korkut@ege.edu.tr

How to cite this paper:

Özkesici, B., Korkut, A.Y., Kop,A. \& Babaoğlu,A.Ö. (2016). The effect of vaccination on feeding and growth of European Sea Bass (Dicentrarchus labrax L.,1758) (in Turkish with English abstract). Ege Journal of Fisheries and Aquatic Sciences, 33(2): 157-162. doi: 10.12714/egejfas.2016.33.2.10

\begin{abstract}
Öz: Bu çalışma İzmir'in Çeşme ilçesindeki Gerence Körfezinde yer alan özel bir su ürünleri yetiştiricilik işletmesine ait çipura-levrek üretim tesisinde toplam 91 gün

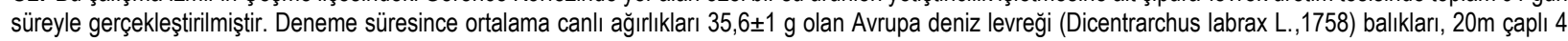
adet dairesel ağ kafes içinde 50.000'er adet olacak şekilde yerleştirilmiştir. Ağ kafeslerden A1 ve A2 (grup A) grubunda olan balıklara aşı uygulaması yapıımış, B1 ve B2 (grup B) grubunda yer alanlara ise aşı uygulaması yapılmamış ve bu gruptaki balıklar kontrol grubu olarak ayrılmıştır. Çalışma süresince ortam koşulları ve enjeksiyon yöntemiyle aşı yapılan levrek yavrularının aşı yapılmayanlara göre gelişimleri karşılaştırılmış, Mortalite oranları, Yem Dönüşüm oranı (FCR), Kondüsyon faktörü (CF) ve Spesifik Büyüme Oranı (SGR) değerleri tespit edilmiştir. Buna göre aşılamanın gelişim üzerinde pozitif etkisi olduğu gözlenmiş ve sonuçlarla ilgili önerilerde bulunulmuştur.
\end{abstract}

Anahtar kelimeler: Avrupa Deniz Levreği, Dicentrarchus labrax, Aşılama, Gelişim, FCR, SGR, CF

Abstract: : This study had been performed at gilthead sea bream-sea bass production facility of a special aquaculture company in Çeşme Gerence Bay Region of İmir for 91 days in total. In testing period, European sea basses which have $35,6 \pm 1 \mathrm{~g}$ average initial weight were put into 4 circular net cages in $20 \mathrm{~m}$ dimension. 50000 fishes were used in each cage. Fishes in A1 and A2 (group A) net cages group were vaccinated with injection method. Fishes in B1 and B2 (group B) net cages group were not vaccinated and they seperated as control group. Environmental conditions and growth rates of vaccinated and unvaccinated sea basses were compared during the research period and Mortalite ratio, Feed Conversion Rate (FCR), Condition Factor (CF) and Specific Growth Rate (SGR) were determined. According to this, there had been observed that vaccination had possitive effect on growing and there were made suggestions about the results.

Keywords: European Sea Bass, Dicentrarchus labrax, Vaccination, Growing, FCR, SGR, CF

\section{GíRiş}

Son yıllarda artan su ürünleri üretim miktarlarına paralel olarak, yetiştiricilik içinde maliyeti arttıran en önemli kalem olan yemin yanında balık hastalıkları da ikinci sırayı almaktadır. Çünkü üretimdeki bu büyüme ve çevresel etkileşimlerle birlikte bakteriyel, viral, fungal ve paraziter hastalıklarda da artış meydana gelmektedir. Balık hastalıkları nedeniyle Avrupa'da ve dünyada üretilen balıkların kalitesinde ve miktarında önemli ölçüde kayıpların olduğu bildirilmektedir. (Hill, 2005; Neary vd.,2008). Hastalıklar ekonomik kayıplara neden olmaları yanında ayrıca ihracatı olumsuz yönde etkilemeleri, ilaç masraflarının üretim maliyetini arttırması, bilinçsiz kullanılan ilaçların rezidü sorunu yaratmaları ve çevre kirliliği oluşturmaları, Bakteriyel direnci artırmaları ve bunların sonucunda da iş ve zaman kaybına yol açmaları nedeniyle (c) Published by Ege University Faculty of Fisheries, Izmir, Turkey kesinlikle kontrol altında tutulması gereken bir konudur.

Balıkları hastalıklardan koruma konusunda birçok yöntem bildirilmekte olup, bu yöntemler hastalık etkenine göre değişmektedir. Balık hastalıklarının kemoterapotiklerle tedavisi çoğunlukla ekonomik değildir. Ayrıca çevre kirliliği, rezidü gibi birçok nedenle ilaç uygulamaları sınırlandırımaktadır. Profilaktik amaçla kemoterapötiklerin kullanılması, bakterilerde direnç gelişimine yol açarken, balık etindeki kemoterapötik kalıntıları tüketici sağlığını olumsuz yönde etkilemektedir. Ayrıca kemoterapötiklerle tedavi edilen balıklarda birkaç ay gibi kısa bir süreç sonrasında hastalıkların nüksettiği görülmektedir (Tanrıkul, 1995). Viral balık hastalıklarının tedavisi ise mümkün olamamaktadır. 
Akhan vd., (2003), oksitetrasiklinin levrek balıkları üzerine etkisi ile ilgili hazırladıkları araştırmaları sonucunda, oksitetrasiklinin levrek kanındaki toplam lökosit sayısını azalttığını bildirmiştir. Hastalıklardan korunmada en geçerli yöntemler; hijyenik tedbirlerin alınması, hasta ve portörlerin işletmeye sokulmaması ve balıkların aşılanmasıdır.

Tüm bu nedenlerle balık hastalıklarının önlenmesi amacıyla aşı geliştirme çalışmaları önem kazanmış olup, ticari aşılar geliştirilmiştir. Bu süreç de balık çiftliklerinin gelişmesine ve çarpıcı biçimde antibiyotik kullanımının azalmasına neden olmuştur (Sommerset et al.,2005; Adams ve Thompson, 2006).

Günümüzde virülensi yüksek insan ve hayvan hastalıkları aşılama ile kontrol altına alınabilmektedir. Balık hastalıkları için; Yersinia ruckeri,Vibrio anguillarium, Pasteurella piscicida ve Aeromonas salmonicida bakterileri ile ticari aşılar geliştirilmiştir. Bunlardan vibriozis, yersiniozis, frunkulozis ve pasteurellosis aşıları ticari olarak yaygın bir şekilde kullanılmaktadır (Johnson vd., 1982). Balık hastalıkları konusunda son yıllarda yapılan çalışmalar, mikroorganizmaların işletmeye girmeden önlenmesinin şart olduğunu ortaya çıkarmıştır. Çünkü bu tip durumlar ekonomik kayıplara neden olabilmektedir. Bu nedenle koruyucu önlemlerin alınması ile ciddi ve devamlı bir şekilde uygulanması gereklidir. Koruyucu önlemler arasında balıkların immunizasyonla korunması önem arz etmek olup, hastalıklardan korunma uygulamalarında ilk sırayı almaktadır. Çağırgan (2004) Levreklerde vibriosisten korunmada uygulanan banyo, enjeksiyon ve oral yolla yapılan aşılar içerisinde en kolay uygulananının oral yol olduğunu bildirmektedir.

Balıklarda aşılamanın, hastalıklardan kaynaklanan ölüm, verim kayıpları, tedavi için kullanılan giderlerin ve ilaç kullanılması sonucu oluşan çevre kirliliği ile balık ve diğer deniz ürünlerinde rezidü sorunlarının azaltılması yanında, yemden yararlanmayı ve gelişmeyi arttırma gibi olumlu etkileri bulunmaktadır.

Viale vd., (2006), yaptıkları çalışmalarında, off-shore kültüründe yetiştirilen levrek balıklarını vibriozis hastalığına karşı banyo yöntemiyle aşılamış, bir yıl boyunca aşılı balıkların toplam üretiminin $(\mathrm{kg})$ aşısız balıklara göre en az \%10 oranında daha yüksek olduğunu bildirmiştir.

Bunların yanında anestezi, aşılarda adjuvan kullanımı vb. gibi uygulamaların oluşturduğu strese bağlı yem alımı ve büyüme negatif yönde etkilenebilmektedir (Midtlyng, 1996; Berg vd.,2007; Neary vd.,2008). Ancak balıkların aşılamadan sonraki ilk iki hafta içerisinde yem alımının azaldığı, üçüncü haftadan itibaren ise bu durumun normal seviyelere geldiği bildirilmektedir (Midtlyng vd., 1996; Rønsholdt ve McLean, 1999; Sørum ve Damsgard, 2004; Koskela vd., 2004). Ayrıca aşı uygulamalarının diğer yetiştiriciliği yapılan canlı gruplarında olduğu gibi tüketici sağlığı üzerinde herhangi bir olumsuz etkisinin olmadığı da vurgulanmıştır (Türk, 2000).

$\mathrm{Bu}$ çalışmanın amacı, yağ bazlı ticari bir aşının Levrek balıklarının yem alımı, büyüme ve gelişmeleri üzerine etkilerinin araştııılmasıdır.

\section{MATERYAL VE YÖNTEM}

Bu araştırma İzmir İli, Çeşme İlçesi Gerence Körfezi mevkiinde yer alan özel bir su ürünleri yetiştiricilik işletmesine ait çipura ve levrek üretim tesisinde gerçekleştirilmiştir. Çalışma $20 \mathrm{~m}$ çap ve $10 \mathrm{~m}$ derinlikte 4 adet dairesel HDPE özellikte ağ kafeste uygulanmıştır. Çalışmada her ağ kafeste 50 bin adet olmak üzere toplamda 200 bin adet ortalama canlı ağırlıkları $35,4 \pm 1$ g olan levrek (Dicentrarchus labrax L., 1758) balığı kullanılmıştır.

Buna göre iki ağ kafes için aşı uygulaması yapıımış (A1 A2) diğer iki ağ kafese ise aşı uygulaması yapıımamış (B1 - B2) ve kontrol grubu olarak ayrılmıştır. A1 ve A2 kafeslerinde ki balıklarda aktif bileşenleri formalin ile inaktive edilmiş Photobacterium damselae subsp. piscicida ve Listonella anguillarum (serotip 01) ile katkı maddesi non-mineral yağ olan divalent ticari aşı kullanılmıştır.

Deneme balıklarının beslenmesinde kullanılan yem özel bir firma tarafından ticari özellikte pelet formunda extrude olarak üretilmiş 2-3 mm çaplı Levrek Büyütme yemidir. Yemde kullanılan hammaddeler; balık unu, soya küspesi, balık yağı, buğday unu, buğday gluteni, bezelye proteini, mısır gluteni, vitamin ve mineral olup, yemlere ait besin madde özellikleri Tablo 1'de belirtilmiştir.

Tablo 1. Deneme yemlerine ait besin madde değerler Table 1. Nutritional components of experimental feed

\begin{tabular}{lcc}
\hline Besin Madde & 2 $\mathbf{~ m m ~ C ̧ a p l ı ~ Y e m ~}$ & 3 mm Çaplı Yem \\
\hline Ham Protein min. (\%) & 48 & 46 \\
Ham Yağ min. (\%) & 18 & 18 \\
Ham Selüloz max. (\%) & 1,5 & 2 \\
Ham Kül max. (\%) & 11 & 11 \\
Nem max. (\%) & 10 & 10 \\
NFE max. (\%) & 18 & 18 \\
Enerji (Kcal) min. & 4500 & 4350
\end{tabular}

Vitamin A 18.000 (IU/kg), Vitamin D3 2500 (IU/kg), Vitamin E 250 (mg/kg), Vit. C $240(\mathrm{mg} / \mathrm{kg})$, Choline $600(\mathrm{mg} / \mathrm{kg})$

Balıkların deneme başından itibaren her 30 günde bir deneme kafeslerinden rastgele örnekleme ile seçilerek biyometrik ölçümleri gerçekleştirilmiştir. Bu amaçla canlı ağırlık ölçümleri için 0,01 $\mathrm{g}$ hassasiyetli terazi ve boy ölçümleri için boy ölçme cetvelinden yararlanılmıştır. Su koşulları için multi parametre cihazı ile su sıcaklıkları ve çözünmüş oksijen ölçümleri gerçekleştirilmiştir.

Çalışmanın gerçekleştirildiği özel işletmede mevcut olan ağ kafesleri deneme için $A$ ve $B$ grubu olacak şekilde dizayn edilmiştir. A grubu balıklar aşı uygulamasından önce bir gün boyunca aç bırakılmıştır. Aynı şekilde kontrol grubunu oluşturan grup için de yem uygulaması yapılmamıştır. Çalışma 
Eylül - Kasım Ayları arasında toplam 91 gün süre ile gerçekleştirilmiştir.

Aşılama işlemi için balıkların deneme kafeslerine alınmadan önce tamamı (50bin adet) branda içinde stoklanarak fenoksi-etanol ile $(0,1 \mathrm{ml} / \mathrm{l})$ anestezi altına alınmıştır. Denemede kullanılacak aşının oda sıcaklığına ulaşmas beklenmiş, uygulama için çalkalanarak hazır hale getirilmiştir. Uygulama her bir balık için $0,1 \mathrm{ml}$ olacak şekilde balığın peritonal kavitesine 45 derecelik açı ile enjeksiyon şeklinde uzman aşı firması desteği ile gerçekleştirilmiştir. Araştırma süresince balıklara sabah ve akşam olmak üzere adlibitum (yem alımı kesilene kadar) yem verilmiştir. Deneme süresince ağ kafeslerdeki su sıcaklığı ve çözünmüş oksijen günlük olarak ölçülmüştür. Balıkların büyüme ve yem değerlendirme oranlarının belirlenebilmesi için aşağıdaki formüllerden yararlanılmıştır. (Bassompierre vd., 1998.; McLean vd., 1997. Korkut vd., 2007);

FCR = Tüketilen yem $(\mathrm{Kg})$ / Kazanılan toplam canlı ağırlık (Kg), SGR $=(($ InW2 - InW1 ) / t (gün) $) \times 100$,

$C F=\left(W / L^{3}\right) \times 100$

Deneme süresince elde edilen veriler istatistiki değerlendirmeye alınmış ve bu işlem için SPSS 8,1 istatistik programı kullanılmıştır. İstatistiksel değerlendirmede tek yönlü Anova uygulanmış, daha sonra gruplar arasındaki farklılık için grupların karşılaştırımasında bağımsız t-testi'nden yararlanılmıştır. Tüm testlerde yanılma düzeyi $>95 \%(P<0,05)$ olarak kabul edilmiştir.

Tablo 3. Deneme gruplarına ait büyüme ve gelişme parametreleri Table 3.Growth and development parameters belongs to trial groups

\section{BULGULAR}

Deneme süresince balıkların büyüme ve gelişmeleri üzerine etkin olan ortam koşulları (su sıcaklık ve çözünmüş oksijen) ile tüketilen yem miktarları değerleri için elde edilen verilere bağlı olarak sonuçlar değerlendirilmiştir. Bu amaçla günlük yem miktarları, ölü balık sayıları ve su koşulları izlenmiş ve kayıt altına alınmıştır. Buna göre su sıcaklık değerlerinin aylara göre dağılımları Tablo 2'de belirtilmiştir.

Tablo 2. Ortalama su sıcaklıklarının aylara göre değişimleri $\left({ }^{\circ} \mathrm{C}\right)$ Table 2. Average water temperature changes by months $\left({ }^{\circ} \mathrm{C}\right)$

\begin{tabular}{lllll}
\hline AYLAR & N & MiN. & MAX. & ORT. \\
\hline EYLÜL & 28 & 23,0 & 24,8 & $23,7 \pm 0,38$ \\
EKIM & 26 & 19,4 & 22,2 & $21,1 \pm 0,51$ \\
KASIM & 26 & 17,3 & 20,2 & $19,4 \pm 0,49$ \\
\hline
\end{tabular}

Su sıcaklığı ile birlikte alınan çözünmüş oksijen değerlerinin ortalaması $6,4 \pm 0,15 \mathrm{mg} / \mathrm{l}$ şeklinde olmuştur. Bu süreç içinde minimum değer Eylül ayında 5,8 $\pm 0,28 \mathrm{mg} / \mathrm{l}$ ve maximum değer ise Kasım ayı içinde $7,4 \pm 0,14 \mathrm{mg} / \mathrm{l}$ olacak şekilde ölçülmüştür. Gözlenen bu değerlerin deneme balıklarının yetiştiricilik koşullarını negatif yönde etkileyecek bir etkisinin olmadığı dikkate alınmıştır (Korkut vd., 1995).

Deneme süresince elde edilen biyometrik ölçüm sonuçlarına göre canlı ağılık ve total boy değişimleri ile yemden yararlanma (FCR), büyüme oranı ( $S G R)$, kondüsyon faktörü (CF) ve mortalite sayıları (adet) Tablo 3'te belirtilmiştir.

\begin{tabular}{lllll}
\hline Parametre & A1 & A2 & B1 & B2 \\
\hline İlk Ortalama Canlı Ağırlık (g) & $35,0 \pm 1,2$ & $36,2 \pm 1,3$ & $35,7 \pm 0,9$ & $35,4 \pm 1,0$ \\
Son Ortalama Canlı Ağırık(g) & $100.3 \pm 2,0^{\mathrm{b}}$ & $102,8 \pm 1,8^{\mathrm{b}}$ & $88,4 \pm 1,4^{\mathrm{a}}$ & $87,6 \pm 1,2^{\mathrm{a}}$ \\
Kazanılan Canlı Ağırlık (g) & 65,3 & 66,6 & 52,7 & 52,2 \\
İlk Ortalama Total Boy. (cm) & $16,03 \pm 0,4$ & $16,1 \pm 0,6$ & $16,9 \pm 03$ & $16,5 \pm 0,2$ \\
Son Ortalama Total Boy. (cm) & $21,2 \pm 0,2^{\mathrm{a}}$ & $21,4 \pm 0,4^{\mathrm{a}}$ & $19,8 \pm 0,5^{\mathrm{a}}$ & $19,6 \pm 0,5^{\mathrm{a}}$ \\
İlk Balık Sayısı (adet) & 50000 & 50000 & 50000 & 50000 \\
Son Balık Sayısı (adet) & 48305 & 48460 & 41870 & 43435 \\
Mortalite (adet) & $1695^{\mathrm{b}}$ & $1540^{\mathrm{b}}$ & $7130^{\mathrm{a}}$ & $6565^{\mathrm{a}}$ \\
Mortalite (\%) & $3,39^{\mathrm{b}}$ & $3,08^{\mathrm{b}}$ & $14,26^{\mathrm{a}}$ & $13,13^{\mathrm{a}}$ \\
Kazanılan Biyomas (kg) & $3154,30^{\mathrm{b}}$ & $3227,44^{\mathrm{b}}$ & $2206,55^{\mathrm{a}}$ & $2267,31^{\mathrm{a}}$ \\
FCR & $2,02^{\mathrm{b}}$ & $1,93^{\mathrm{b}}$ & $2,55^{\mathrm{a}}$ & $2,54^{\mathrm{a}}$ \\
SGR & $1,15^{\mathrm{b}}$ & $1,14^{\mathrm{b}}$ & $0,99^{\mathrm{a}}$ & $0,99^{\mathrm{a}}$ \\
CF & $1,053^{\mathrm{b}}$ & $1,048^{\mathrm{b}}$ & $1,139^{\mathrm{a}}$ & $1,163^{\mathrm{a}}$
\end{tabular}

FCR: Yem dönüşüm oranı, SGR: Spesifik büyüme oranı, CF: Kondüsyon faktörü. Farklı üstlü sayılar (a,b) gruplar arasındaki farklıı̆ı göstermektedir. 
Çalışma başlangıcında balıkların ortalama canlı ağırlık ve total boy değerleri dikkate alındığında gruplar içinde ve deneme grupları arasında önemli bir fark $(P>0,05)$ gözlenmemiştir (Çizelge 3). Benzer şekilde, deneme sonunda aşılı grup ( $A 1$, $A 2)$ ile aşısız grup (B1, B2) içinde önemli bir fark bulunmamıştır $(P>0,05)$. Ancak aşılı ve aşısız gruplar $(A$ ve $B)$ arasında büyüme, yemden yararlanma, $S G R, C F$ ve mortalite bakımından önemli farklar bulunmuştur $(P<0,05)$.

\section{TARTIŞMA VE SONUÇ}

Çalışma süresince ölçülen su koşullarına ait değerler mevsim ortalamalaması içinde olup, aşı uygulaması yapılan ve yapılmayan balıkların yetiştiricilik koşulları açısından herhangi bir olumsuz etkisi tespit edilmemiştir. Zanuy ve Carillo (1985) levrek balığının hem deniz suyu hem de acı suda iyi bir yem değerlendirme oranı için optimum su sıcaklığının $19-25^{\circ} \mathrm{C}$ arasında olduğunu bildirmektedirler. $\mathrm{Bu}$ türe ait su sıcaklıklarına bağlı olarak optimum yem değerlendirme oranları üzerinde yapılan diğer bir çalışmada, LeRuyet et al (2004), 13 $16,19,22,25$ ve $29^{\circ} \mathrm{C}$ 'lerde $80 \pm 1 \mathrm{~g}$ ortalama canlı ağırlıklarda olan jüvenil Avrupa deniz levreklerinde büyüme ve gelişme performansları incelenmiş ve buna göre, $29^{\circ} \mathrm{C}$ su sıcaklığına kadar adapte olduğunu ve en iyi gelişmenin $25^{\circ} \mathrm{C}$ 'de gerçekleştiği belirtilmiştir.

Benzer şekilde, Pylkko vd., (2002), alp alabalıklarında (Salvelinus alpinus) aşılmanının immun sistem üzerindek etkilerini 3 ayrı sıcaklıkta $\left(10,3\right.$ ve $14,1,18,1{ }^{\circ} C^{\prime}$ de $)$ incelemişler, sonuçta tüm gruplarda aşılamanın koruyucu etkisinin olduğunu ve bu nedenle aşı etkinliğini arttırmak için bu türün daha yüksek sıcaklıklarda tutulmasının gereksiz olduğunu, balıkların en iyi geliştikleri optimum koşulların aşılama etkinliği bakımından da yeterli olduğunu bildirmişlerdir.

Aşılı (A) ve kontrol (B) gruplarında çalışma süresince hastalık belirtileri gözlemlenmemiştir. Çalışmanın ilk iki ayında balıkların yem alımında ve buna bağlı olarak ağırlık artışında önemli bir farklılık gözlenmemiştir. Ancak Kontrol grubundaki balıkların çalışma sonunda aşılı balıklardan önemli derecede $(P<0,05)$ düşük ağırlıkta oldukları tespit edilmiştir. Bu durum su sıcaklığının ortalama $19,4^{\circ} \mathrm{C}$ 'ye indiği Kasım ayında grupların toplam yem tüketim miktarında da (A grubu; 1875 g/ay ve $B$ grubu; 1275 g/ay) kendini göstermiştir.Benzer şekilde, Viale vd., (2006), off-shore kafeslerdeki Avrupa Deniz Levreklerinde Vibriosise karşı uyguladıkları ticari aşı uygulaması sonucunda, aşılı gruptaki balıkların kontrol grubu balıklarına oranla çok daha iyi geliştiklerini bildirmişlerdir. Ancak çalışmada elde edilen bu sonucun aksine Lillehaug (1991) alabalıklarda vibriozise karşı aşı uygulaması üzerine yaptığı çalışmada aşısız grupta ağırlık artışının aşılananlara oranla daha yüksek olduğunu gözlemlemiştir. Bunun sebebi olarak da aşının balık üzerindeki yan etkilerini göstermiştir. Özellikle yağ katkı maddesi içeren aşıların yan etkileri; enjeksiyon bölgesindeki lezyonlar (Midtlyng vd., 1996b), bazı iç organlarda yapışma (Midtlyng, 1996) olarak bildirilmiştir. Bununla beraber bazı araştırıcılar Atlantic salmon (Salmo salar L.) (Midtlyng vd., 1996b; Sørum ve Damsgard, 2004) ve gökkuşağı alabalığında
(Oncorhynchus mykiss) (Rønsholdt ve McLean, 1999),aşılamadan 2-4 hafta arasında iştahın azaldığını ve dolayısı ile aşılanan balıkların kontrol grubuna oranla büyümede önemli derecede düşük kaldıklarını, iştahın bu sürelerden sonra tekrar geri kazanılarak kontrol gruplarılyla aynı seviyeye geldiği bildirmektedirler (Rønsholdt ve McLean, 1999; Koskela vd.,2004).

Çalışma sonunda 4 grup içinde FCR değerleri hesaplanmıştır. Buna göre A1 grubu için 2.02, A2 için 1.93, B1 için 2.55, B2 içinse 2.54 olarak bulunmuştur. Çalışmada elde edilen FCR değerleri aşılı grupta yemin çok daha verimli kullanıldığını ve gruplar arasında önemli bir farklılık olduğunu göstermektedir $(P<0,05)$. Bununla beraber tüm gruplar için FCR değerleri yetiştiricilikte kabul gören değerler arasında kalmaktadır ( FCR tankta 1.88 Lanari et al., 1991; ağ kafeste 2.4 Korkut ve diğ. 1995). Ancak Koskela vd., 2004 yaptıkları çalışmada aşılamanın yemden yararlanma oranı üzerine etkili olmadığını vurgulamaktadır.

Deneme sonunda SGR değerleri tüm gruplar için hesaplanmış ve $A 1$ için 1,15, A2 için 1,14, B1 ve B2 içinse 0,99 olarak hesaplanmıştır. Deneme gruplarının büyüme oranı bakımından değerlendirilmesi yapıldığında aşıı balıkların aşıSız balıklara oranla önemli derecede farklılık $(P<0,05)$ gösterdiği bulunmuştur

Koskela vd., (1997), kondisyon faktörü 1'e eşitse balığın iyi şartlarda büyüdüğünü, 1.0'den büyükse yağlı olduğunu ifade etmektedir. Bu çalışmada bütün gruplar için hesaplanan kondisyon faktörü $A 1$ ve $A 2$ grupları için 1,053 ve 1,048, B1 ve B2 grupları için 1,139 ve 1,163 olarak bulunmuştur. Aşılanan balıkların kondüsyon faktörü kontrol grubuna oranla önemli derecede iyi olduğu tespit edilmiştir $(P<0,05)$. Korkut vd., (1995) Levrek balıklarında yetiştiricilik şartları altında kondisyon faktörünün 0.65 ile 1.29 arasında olduğunu belirtmektedirler. Buna göre tüm gruplar için elde edilen kondisyon faktörü değerlerinin optimum değerler arasında kaldığı söylenebilir.

Bu çalışmada elde edilen mortalite oranlarına bakıldığında ise aşı uygulaması yapılan $A 1$ ve $A 2$ kafeslerinde sırasıyla \% 3,39 ve 3,08 olurken bu oran B1 ve B2 grubunda $\% 14,26$ ve 13,13 'tür. Yapılan istatistiki değerlendirmeye göre aşılı ve aşıSız gruplar arasında mortalite bakımından önemli derecede farklılık olduğu $(P<0,05)$ saptanmıştır. Özellikle mortalite oranının kontrol grubu için su sıcaklığının düştüğü aylarda yükseldiği gözlenmiştir (B1 7130, B2 6565 adet). Çalışmada elde edilen sonuca benzer şekilde Lillehaug (1990) yaptığı çalışmada, ortalama mortalite oranının aşılı balıklarda $\% 1,87$, aşıSIZ balıklarda ise \%24,9 olduğunu bildirmiştir. Angelidis (2006), 3,3g'lık levrek balıklarına vibriozise karşı banyo yöntemiyle aşı uygulaması yapmıştır. Bu enjeksiyondan 30 gün sonra test edilen gruplardan $2 \mathrm{kez}$ aşılama yapılanlarda $\% 0,1$ kez aşılananlarda $\% 10$, kontrol grubunda ise $\% 50$ oranında mortalite görüldüğünü bildirmiştir. Çalışmada enjeksiyon yöntemiyle aşılama güçlü bir bağışıklık sağladığı için 2. kez aşılama yapılmasına gerek olmadığı tespit edilmiştir. Ancak 
banyo ya da oral yöntemle yapılan aşılamalarda 2 . kez aşılama yapılması önerilmektedir (Hjeltnes,1989; Lillehaug,1997).

Siwicki vd., (2002), aşılamanın koruyuculuk etkisi ve dayanma süresi üzerine, ortamdaki ve uygulama sırasında balıkların maruz kaldıkları stresin çok önemli bir faktör olduğunu bildirmiştir. Bu araştırmacılar yaptıkları çalışmada aşılama sırasında kullanılan anestezinin spesifik ve nonspesifik savunma mekanizmaları üzerindeki pozitif etkisini göstermiştir. Çalışma sonucunda kümülatif mortalitenin anestezi kullanılanlarda enjeksiyon yönteminde $\% 5$, banyo yönteminde $\% 10$, anestezisiz aşılananlarda enjeksiyon yönteminde $\% 20$, banyo yönteminde $\% 35$ kontrol grubunda ise $\% 80$ olarak ortaya çıktığı bildirilmiştir.

Balıklarda aşılamanın sağladığı yararlar artık tüm dünya tarafından kabul edilmektedir. Yapılan bazı çalışmalar özellikle enjeksiyon yöntemiyle aşılanan balıklarda iştahın beli bir süre azaldığını göstermektedir. Bu durumun en önemli sebepleri

\section{KAYNAKÇA}

Adams, A., \& Thompson, K. D. (2006). Biotechnology offers revolution to fish health management. Trends in Biotechnology, 24 (5), 201-205. doi: 10.1016/j.tibtech.2006.03.004

Akhan, S., Tanrıkul, T., T., Balta, F. \& Serezli, R. (2003). Analyzing the effect of oxytetracycline on phagocytic activity of neutrophiles in sea bass (Dicentrarchus labrax L.,1758) (in Turkish with English abstract). Firat Üniversitesi Science and Engineering Sciences Magazine, 15(3):1300 2708.

Angelidis, P. (2006). Immersion booster vaccination effect on sea bass (Dicentrarchus labrax L.) juveniles. Journal of Animal Physiology and Animal Nutrition, 90:1-2, P.46-49. doi: 10.1111/j.1439-0396.2005.00572.x

Bassompierre, M., Ostenfeld, T.H., McLean, E., \& Torrissen, K. (1998). Growth and in vitro protein digestion of Atlantic salmon with genetically different trypsin isozymes. Aquaculture International (6), 47-56. doi: 10.1023/A:1009269703297

Berg, A., Rodseth, O.M., \& Hansen, T. (2007). Fish size at vaccination influence the development of sideeffects in Atlantic salmon (Salmo salar L.) Aquaculture, (265), 9-15. doi:10.1016/j.aquaculture.2007.02.014

Buchmann, K., Dalsgaard, I., Nielsen, M.E., Pedersen, K., Uldal, A., Garcia, J.A., \& Larsen, J.L. (1997). Vaccination improves survival of Baltic salmon (Salmo salar) smolts in delayed release sea ranching (net-pen period). Aquaculture (156), 339-351.

Çağırgan, H. (2004). Vaccine development in sea bass fry (Dicentrarchus labrax L., 1758) against vibriosis (in Turkish with English abstract). Ege Journal of Fisheries and Aquatic Sciences, (21), (3-4): 271- 274

Hill, B.J. (2005). The need for effective disease control in international aquaculture. Development in Biological Standardization, (121), 3-12.

Hjeltnes, B., Andersen, K., \& Ellingsen, H.M. (1989). Vaccination against Vibrio salmonicida: the effect of different routes of administration and of revaccination. Aquaculture, (83) 1-2, 1-6. doi: 10.1016/0044-8486(89)90055-0

Johnson, K.A., Flynn, J.K., \& Amend, D.F. (1982). Duration of immunity in salmonids vaccinated by direct immersion with Yersinia ruckeri and Vibrio anguillarum bacterins. Journal of Fish Diseases, 5:3, 207-213. doi: 10.1111/j.1365-2761.1982.tb00475.x

Kitlen, J.W., Hejbøl, E.K., Zinck, T., Varming, K., Byatt, J.C., \& McLean, E. (1997). Growth performance and respiratory burst activity in rainbow trout treated with growth hormone and vaccine. Fish and Shellfish Immunology (7), 297-304. doi: 10.1006/fsim.1997.0085 arasında anestezinin yan etkisi ve kullanılan enjektörün balıklarda yaralanmaya neden olması gelmektedir (Midtlyng vd., 1996 ; 1996b). Ancak yağ katkılı aşıların kullanıldığı kısa süreli çalışmalarda (2 aydan az süreli) bu sonuçlar görülürken (Kitlen vd., 1997; Rønsholdt ve McLean, 1999; Pylkko vd., 2000; Melingen ve Wergeland, 2002; Sørum ve Damsgard, 2003), özellikle uzun dönemli aşı çalışmalarında gelişimin aşısız gruplara oranla benzer şekilde veya çok daha iyi olduğu da belirtilmektedir (Lillehaug,1991; Buchmann vd., 1997; Midtlyng ve Lillehaug, 1998; Pylkko vd., 2002).

Sonuç olarak, yapılan bu çalışmada aşılamanın Levrek balıklarının büyüme, yem değerlendirme ve kondüsyon faktörleri üzerine olumlu etkileri olduğu, mortalite oranını önemli düzeyde düşürdüğü belirlenmiștir. Buna göre aşısız gruptaki balıklardaki mortalitenin ve FCR değerlerinin yükselmesi çalışmanın son ayının su sıcaklıklarının düştüğü döneme rastlamış olması ile ilişkilendirilebilir.

Korkut, A. Y., Temelli, B. \& Vural, A. F. (1995). A research on feeding and growing of sea basses (Dicentrarchus labrax L., 1758) in different water temperatures (in Turkish with English abstract). S.D.Ü. Journal of Eğirdir Faculty of Fisheries, (4):201-210.

Korkut, Y.A., Kop, A., Demirtaş, N., \& Cihaner, A. (2007). Monitoring Methods of Growth Performance in Fish Feding. (in Turkish with English abstract). Ege Journal of Fisheries and Aquatic Sciences, 24 (1-2): 201-205.

Koskela, J., Pirhonen, J. \& Jobling, M. (1997). Growth and Feeding Responses of a Hatchery Population of Brown Trout (Salmo trutta L.) at Low Temperatures. Ecology of Freshwater Fish, (6): 116-121. doi: 10.1111/j.1600-0633.1997.tb00152.x

Koskela, J., Rahkonen R. Pasternack M., \& Knuutinen H. (2004). Effect of immunization with two commercial vaccines on feed intake, growth, and lysozyme activity in European whitefish (Coregonus lavaretus L.). Aquaculture (234), 41-50. doi: 10.1016/j.aquaculture.2003.11.036

Lanari, D., Ballestrazzi, R., Tulli, F. \& Tibaldi, E. (1991). Effect of Dietary Fatty Acids Ca Salt on Performance and Body Composition on Juvenile Sea Bass (Dicentrarchus labrax L.), IV.International Symposium on Fish Nutrition and Feeding, Piarritz, 891 - 896. In: Akbulut, B., Şahin, T., Aksungur, M., Aksungur, N., Ertegen, A., 1999, Sea Bass Aquaculture in Black Sea, Central Fisheries Research Institute, Trabzon.

LeRuyet, P., Mahé, K., Le Bayon, N \& LeDelliou, H. (2004). Effects of temperature on growth and metabolism in a Mediterranean population of European sea bass, Dicentrarchus labrax. Aquaculture, 237 (1-4): 269280. doi: 10.1016/j.aquaculture.2004.04.021

Lillehaug, A. (1990). A field trial of vaccination against cold-water vibriozis in Atlantic salmon (Salmo salar L.). Aquaculture, 87:1, 1-12. doi:10.1016/0044-8486(90)90295-X

Lillehaug, A. (1991). Vaccination of Atlantic salmon (Salmo salar L.) against cold-water vibriozis duration of protection and effect on growth rate. Aquaculture, 92 (2-3), 99-107. doi:10.1016/0044-8486(91)90011-U

Lillehaug, A. (1997). Vaccination strategies in seawater cage culture of salmonids. Development of Biology. (90):401-8.

McLean, E., Devlin, R.H., Byatt, J.C., Clarke, W.C. \& Donaldson, E.M. (1997). Evaluation of a controlled release formulation of recombinant bovine growth hormone on growth and seawater adaption in coho Oncorhynchus kisutch and chinook O. tshawytscha salmon. Aquaculture (156), 113-128. doi: 10.1016/S0044-8486(97)00071-9

Melingen, G.O., \& Wergeland, H.I. (2002). Physiological effects of an oiladjuvanted vaccine on out-of-season Atlantic salmon (Salmo salar L.) smolt. Aquaculture (214), 397-409. doi:10.1016/S0044-8486(01)00867-5 
Midtlyng, P.J. (1996). A field study on intraperitoneal vaccination of Atlantic salmon (Salmo salar L.) against furunculosis. Fish Shellfish Immunology (6), 553-565. doi:10.1006/fsim.1996.0052

Midtlyng, P.J., Reitan, L.J. \& Speilberg, L. (1996b). Experimental studies on the efficacy and side-effects of intraperitoneal vaccination of Atlantic salmon (Salmo salar L.) against furunculosis. Fish Shellfish Immunology (6), 335350. doi:10.1006/fsim.1996.0034

Midtlyng, P.J., \& Lillehaug, A. (1998). Growth of Atlantic salmon Salmo sala after intraperitioneal administration of vaccines containing adjuvant Diseases of Aquatic Organisms (32), 91- 97. doi:10.3354/da0032091

Neary E. T., Develi N., \& Yüksel S. A. (2008). Use of Fish Vaccine in Aquaculture (in Turkish with English abstract). Journal of Agricultural Faculty of Gaziosmanpasa University (JAFAG), 25(2), 29-35.

Pylkko, P., Lyytikäinen, T., Ritola, O.., Pelkonen, S., \& Valtonen E. T. (2002). Temperature effect on the immune defense functions of Arctic charr Salvelinus alpinus. Diseases Of Aquatic Organisms. (52): 47-55. doi:10.3354/dao052047

Rønsholdt, B., \& McLean, E. (1999). The effect of vaccine components upon short-term growth and feed conversion efficiency in rainbow trout. Aquaculture (174), 213- 221. doi:10.1016/S0044-8486(99)00016-2

Siwicki, A., K., Morand, M., Kazun, K., Keck, N., Gtqbski, E., \& Mataczewska, J. (2002). Applıcation of anti-stress products in aquaculture: influence of propiscin on the effectiveness of an anti-Yersinia ruckeri vaccine in rainbow trout (Oncorhynchus mykiss). Archives of Polish Fisheries 10 (2): 143-152.

Sommerset I., Krossoy B., Biering E., \& Frost P. (2005). Vaccines for fish in aquaculture. Expert Review Vaccines 4(1), 89-101. doi:10.1586/14760584.4.1.89

Sorum, U., \& Damsgård, B. (2003). Effects of anaesthetisation and vaccination on feed intake and growth of Atlantic salmon (Salmo salar L.). Aquaculture (232):333-341.

Tanrıkul, T.T. (1995). Bacterial fish vaccines and vaccination methods (in Turkish with English abstract). The Journal of Bornova Veterinary Science (19):33-40

Türk, N. (2000). Vibriosis, yersiniosis, streptococcus infections (in Turkish with English abstract). The Journal of Bornova Veterinary Science (23):23-32.

Viale, L., Cubadda, C., Angelucci, G., \& Salati, F. (2006). Immunization of european sea bass, Dicentrarchus labrax L. 1758, fingerlings with a commercial vaccine against vibriozis: a one year survey on antibody level, diseases and growth. Journal of Applied Aquaculture 18(3). doi: 10.1300/J028v18n03_04

Zanuy, S. \& Carrillo, M. (1985). Annual Cycles of Growth, Feeding Rate, Gross Conversion Efficiency and Hematocrit Levels of Sea Bass (Dicentrarchus labrax) Adapted to Two Different Osmotic Media (in Turkish). Aquaculture, 44, 11 - 25. In: Akbulut, B., Şahin, T., Aksungur, M., Aksungur, N., Ertegen, A., 1999, Sea Bass Aquaculture in Black Sea, Central Fisheries Research Institute, Trabzon. 